\title{
Structural Equation Modelling in Microscoping Nepalese Commercial Banks' Profit Maximization by Risk Minimization
}

\author{
Chakra Bahadur Khadka, PhD \\ Lecturer of Economics, Patan Multiple Campus, Tribhuvan University, Nepal \\ Email: cfalkonet@hotmail.com; chakra@pmcecodtu.edu.np
}

\begin{abstract}
This paper examines the degree to which the commercial banks of Nepal used risk management practices and techniques in dealing with different types of risk. The structural equation modeling (SEM) is applied in this study to analyze profit maximization and risk minimization of commercial banks in Nepal. Symmetry and balance to cover four aspects and four components of risk management and use of quantitative data from Banking and Financial Statistics of NRB is considered in the study. SEM is the cross-sectional statistical modeling. Factor analysis, path analysis and regression equation SLs are used for data analysis. Maximum likelihood estimation is the additional estimation equation. The significant findings of the study are: important types of risk being faced by the commercial banks of Nepal like credit risk, operational risk, and interest rate risk. Study also finds that the Nepalese commercial banks staff members properly understand risk and its management. Most of the components of risk management are very sound. There is a strong, positive relationship between risk management practices and understanding of risk and its management, board and senior management oversight, risk assessment and measurement, ownership structure and presence of separate risk manager. Findings of the paper are limited to the RMPs of commercial banks of Nepal. Results help to understand the current practices of Commercial Banks of Nepal. Findings can be used as a valuable feedback on improvement to RMPs and will be of significance to those who are interested in the banking sector of Nepal.
\end{abstract}

Key words: Profit-maximizing, Risk management, Structural equation modelling, Scale free, Banking sector,

JEL Classification: C38, G21, G32

\section{INTRODUCTION}

Profit-maximization of banks have the same objective as any other firm; so, this question is best answered by drawing on traditional models. Coase (1937) in his classic analysis, the firm replaced as an alternative to market connections, a way of organizing economic activity, of procedures is more efficiently organized in command ways rather than depending on a market price. In these situations, it is more profitable to use a 
firms' structure than to rely on market forces. Banks were specialized in credit risk analysis, and the internalized information meant they could profit from informational economies of scale (Heffernan, 2005).

In the word of Guill(2009) since the origin of banking with the $13^{\text {th }}$ century, a bank's main source of income has always been the spread between interest paid on deposits and interest received on loans. Following this principle, banks successfully maintained the intricate balance of maximizing results and minimizing risks of years. Beginning time of the $21^{\text {st }}$ century, the growing worldwide economy tilted the measure. The equilibrium of supremacy lifted to sales, compelling risk calculation to the wayside. Syndication and securitization of loans allowed the loan originators to sell them to another bank or financial institution, which further reduced a bank's need to evaluate and minimize risk.

Furthermore, Guill (2009) adds that these economic obstructions the successive slowdown had altered the mindsets of banking executives and consumers around the globe. As a result, financial institution leaders ponder critical queries about the right approach to lending, qualified prospect, different types of risk assessment criteria, the structure of sales and credit functions, does the bank to minimize risk, yet regain and sustain profitable growth?

Economic capital or risk capital has become the key concept at the heart of modern risk management. It is not calculated from traditional accounting measures such as book capital or equity capital. Instead, it is derived from our understanding of risk. Since our understanding of risk is always incomplete usually inaccurate, the calculation of risk capital cannot be reduced to a simple formula for static input parameters. The calculation of risk capital is a quest it presents the challenge to understanding the risks of a business, a transaction, or a position. Our ability to estimate risk capital improves only our understanding of risk improves (Guill, 2009; Nguyen \& Christopher, 2019).

Banks and Financial Institutions (FIs) are very important for the growth of any economy. The role of Bank and FIs is similar to that of blood arteries in the human body, they pump financial resources for economic growth of the depositories to where they are required (Shanmugam \& Bourke, 1990). Banks and FIs are key providers of financial services. However, banks and FIs face various types of risk during the course of operation. Generally, risk refers to the possibility of deviation from the expected outcome of an action or event which could bring adverse impacts. In the banking industry, risk refers to the possibility the outcome of an action of the bank, could bring up serious adverse impacts on profitability and performance resulting either direct loss of earnings or capital of the banks. 
Therisk-taking is an inherent element of banking indeed, profits are in part the reward for successful risk taking in business. The bank relies on capital as a buffer to absorb such losses. The impact on risk results in direct loss of earnings, erosion of capital or may result in the imposition of constraints on a bank's ability to meet its business objectives. These constraints could hinder a bank's capability to conduct its business operation smoothly. It may even pose threats to the survival of the banks (Adhikari, 2014).

The banks of the course of financial intermediation are confronted with various types of financial and non-financial risks, like credit risk, interest rate risk, liquidity risk, operational risk, foreign exchange risk etc. Undoubtedly, all banks of the present environment are facing a number of risks such as credit risk, liquidity risk, foreign exchange risk, market risk, interest rate risk, etc. Which may threaten a bank's survival and success. Banking is a business of risk (Al-Tamimi \& Al-Mazrooei, 2007). The types and degree of risks that a bank may be exposed to, depend upon a number of bankspecific variables, macroeconomic variables and other variables. Risk Management is a discipline at the core of every bank and encompasses all activities that affect its risk profile. It involves identification, measurement, monitoring and controlling risks (Adhikari, 2014; NRB, 2018).

Inadequate and poor management of risk leads to financial losses and thus endangers the safety of the bank's deposits. Sound risk management keeps the banks as well prepared for the future. Risk management can be made efficiently through appropriate policies, procedures, and strategies. The board of the directors (BOD), senior management is highly responsible for constructing a strong risk management system. Risk management ensures a clear level of understanding of different kinds of risks and their management among bank's staff members that are responsible for undertaking and managing risks of the behalf of the bank. It also ensures that bank's risk exposure limits established by the BOD and the bank has adequate capital as a buffer to undertake risk.

Modern Banking system in Nepal started with the establishment of Nepal Bank Limited in 1937. Within last seven and a half decades, the number of banks and financial institutions in Nepal has increased tremendously. Currently, Nepalese BFIs had launched varieties of banking products that bring various forms of risks. In the present days, Nepalese banks are facing numbers of risks such as credit risk, liquidity risk, foreign exchange risk, market risk, interest rate risk. There have been a large number of theoretical studies published about risk management in developing country's banking in general. However, the number of the studies on risk management 
practices (RMPs) in Nepalese banking industry is found to be relatively few. This has escalated the research interest in Nepalese BFIs as well.

The directing of this research is to examine the degree to which commercial banks with Nepal, follow effective risk management practices. The study also intends to identify the most important type of risk being faced by the commercial banks of Nepal, assess the level of understanding of risk and its management among staff members of those banks and analyze the important components of risk management system also to examine the maximized of profit of commercial banks by minimizing the risk factor.

\section{LITERATURE REVIEW}

Analyzing and assessing risk management practices has always been an extensive research issue in these eras. A number of research papers have made the empirical studies in the context of large and developed as well as developing economies.

A research published by Odit, Dookhan and Marylin (2011) aimed with the analyze of the degree to which the Mauritian banks use risk management practices and techniques in dealing with different types of risk. The data were collected by primary survey and OLS estimates were used for data analysis. The findings of the study were the three important risks facing the Mauritian banks where market risk followed by operational risk, and credit risk. The Mauritian banks were somewhat efficient in managing risk of diversification of portfolios. The results indicated that there was a significant difference between the variables concerning to diversify locally or internationally. According to the findings, both could be used as a tool for risk management practices, there was a need to stress on foreign exchange exposures depending on the bank's risk appetite.

Another research was carried out by Awdeh, EL-Moussawi, and Machrouh (2011) to study, the regulatory tools such as capital adequacy requirements impact bank risktaking with a focus on the Lebanese banking sector. In this research, two simultaneous equations models were used for panel data analysis the sets of data were 41 commercial banks of 1996 and 2008. The important findings of the study were that higher capital requirements were associated with an increase in risk. The result was a positive correlation between bank profitability an increase in capital, which suggested that Lebanese banks relied on retained earnings to meet capital requirements. The competitive pressures seemed to have no impact on bank capitalization or bank risktaking. The findings showed that larger banks tended to hold lower capital and have better capability to control risk, mainly through diversification and the conclusion was that funding decisions which correlated with risk-taking. 
A research of operational risk management in Indian Banks: issues and challenges by Mehra (2012). The aim of the study was to explore the range of operational risk management practices used by across section of Indian Banks and analyses the impact of size. Reliability Analysis using Cronbach Alpha model was used. Kaiser-MeyerOlkin Measure of Sampling Adequacy and Bartlett's test of sphericity was used to justify the use of factor analysis as a data reduction technique. The Factor analysis has been performed to extract the most important variables in the management of operational risk of Indian Banks. The significance answers to the study were, many banks are keen to develop AMA framework and are gearing up for it by collecting relevant data. The organizational structures differ with banks of their strategies and systems, but there was a consistent trend of operational risk departments reporting to the purview of Chief Risk Officer. Most of the banks (84\%) had initiated the process of identification of operational risk inherent in the product (84\%) and people reflecting the discriminating realization of banks of it. The paper evaluated the present status of risk management approach, human resource and outsourcing policies and challenges in the transition to the advanced approach amongst sample banks.

Likewise, Kumah and Sare's (2013) study compares the risk management practices among commercial banks in Ghana. The empirical analysis was based on a sample of six banks, drawn from a list of 27 banks of Ghana. The targeted sampled banks were the six biggest commercial banks of Ghana, and banks were included in risk management. The multiple regression models were used to examine the determinants of risk management practices among the selected commercial banks. The result undid the major risk management determinants to include: understanding of risk, risk identification, risk assessment and analysis, risk monitoring and controlling system. Risk monitoring and control was not to be the most influencing variable in risk management practice among the banks. The result was a negative relationship between risk management practices and the determinants which include understanding risk and risk identification, risk assessment and analysis, risk monitoring and control were positively related to risk management practices in this study. The findings of another objective exposed that, there was a significant difference in risk management practices, understanding risk, risk identification and risk monitoring and control, except risk assessment and analysis which did not differ across the selected banks.

The target of the study was to investigate the current practices of credit risk management of commercial banks of Kenya. The descriptive research design was used. The findings of Afande (2014) bankers used covenants, credit rationing, loan securitization, and loan syndication as risk management defensives. The factors that influenced effectiveness of credit risk management systems used by commercial banks of Kenya include establishment of a credit policy that outline the scope and allocation 
of bank credit facilities, maintenance a credit administration system that with adequate controls over credit; top management supported; communication of credit guidelines to every officer in the credit department, screening for potential borrowers, employing well trained staff, constant review of the borrowers' liquidity and the use of supportive technology in credit analysis. The internal performance measures of the bank lending used by commercial banks of Kenya include the Basel II criteria and bank profitability, including return to equity, return on assets and return on investment. Other indices were the developed benchmarks that include cost per each completed loan, cost per a thousand dollars of loans, non interest revenue from each loan, loans per employee.

A research was directed towards the determinants of the credit risk of commercial banks of Ghana to understanding the causal factors of credit risk of commercial banking by Adu and Adjare (2015). The data were used from 2007 to 2014 using robust least squares regression analysis. The findings of the study were a significant positive relation between the bank credit risk and leverage. And a negative relationship between the credit risk and management efficiency was found. With regard to the relationship between bank credit risk and profit, the results were a significant negative association. It is recommended that commercial banks should continue to diversify their lending activities to productive sectors to mitigate credit risk. The nexus between bank credit risk and management efficiency, the regression results indicated a significant negative relationship implying that management is able to utilize efficiently their assets to Guillrate adequate interest income for their shareholders.

Another research paper was published by Mutavaand Ali, (2016) to establish the effect of credit risk management on financial performance of commercial banks of Mombasa County and to establishing the effect of liquidity risk management, determine the effect of market risk management and determine the effect of default risk management on credit risked management. Forty-four banks were randomly selected for sample. Descriptive statistics was applied for data analysis. The study found that there was a correlation between liquidities risked management, default risk management and market risk management with the performance of the banks. The banks were directed to open up and share information about other players on market risk, thus involve consultants more in their market risk management.

The issue of the variables that impact the profitability of United Arab Emirates (UAE) banks was analyzed by Mehta and Bhavani (2017). The categorical indication of important bank specific, macroeconomics, and industry explicit variables that have affected UAE banks' profitability by analyzing balanced panel data from 2006 to 2013. Both Islamic and non-Islamic, domestic, commercial banks were measured for the purposes of this study. The research work puts addicted to breaking the 
factors of the productivity of the national profitable investment sector of the UAE. The model includes 19 UAE national banks. The research study's dependent variable comprises size, liquidity, and capital adequacy, as well as independent variables that cover macroeconomic and industry-specific variables. Panel model was used for the analysis. The empirical findings were, the cost efficiency, nontraditional revenue sources, and high asset quality were the most significant bank-specific variables, and bank managers has idea to make future policy decisions. The GDP, a macroeconomic variable, was found to be relevant to the return on assets and return to equity.

Arrawatia, Misra, Dawar and Maitra (2018) estimated of the degree of market power in the Indian banking sector by proposing a Lerner Index which is adjusted for risk. Panel data of 46 banks were selected. The sample represents more than $80 \%$ of the banking system in terms of total assets. Factor input costs, labor, capital and administrative expenses were the selected variables. Empirical Design for the estimate of market power was measured by the charge of the price over marginal cost. Imperfect competition model is used to obtain of the Lerner Index. Marginal cost was calculated by estimating the trans logarithmic costs function. The market power estimated through the adjusted Lerner Index was been continuously declining, particularly post 2008 , that indicates an improvement in competitive condition for the overall period.

The study showed higher competition during the period of liberalization an increase in market power during the phase of consolidation and re-regulation. The later phase observed a revival of competitive conditions post the 2008 financial crises. Despite reforms in the Indian banking industry, banks in India, on an average, are exercising market power ranging between $10 \%$ and $15 \%$. As indicated the risk-adjusted Lerner Index, the Indian banking system exerts much less market power contrary to advise the traditional Lerner index.

The definition of the problem of this research is, what is the practice of understanding the risk management commercial banks of Nepal? How the level of assets is considerate of risk, its management among control associates with those banks and the important components of risk management system? And how to are they maximizing of profit of commercial banks by minimizing the risk factor? To answer the questions a study design is developed with the help of structural equation modeling using mixed data onto commercial banks of Nepal. 


\section{DATA AND METHODOLOGY}

\section{Data}

The logic of inquiry is a synthesis of methods, with conducting the $\mathrm{Q}^{2}$ method of study. Primary qualitative estimation designs of the paradigm were "symmetry and balance" or bipolar scaling method, measuring either positive or negative response to a statement. Likewise, the secondary quantitative design of the paradigm was organized as of Banking and Financial Statistics (Nepal Rastra Bank (NRB), 2010- 2017). The strategies of $\mathrm{Q}^{2}$ method of study were, quantitative data can be analyzed "qualitizing" and qualitative data can be analyzed "quantizing". The first Q of research is based on Nonprobability and Judgmental sample technique. Another Q for the research is based on the variable identification of statistics by NRB publication.

\section{Cronbach Coefficient Alpha}

The Cronbach Coefficient Alpha (Cronbach, 1951) is the truly familiar estimate of internal consistency of items in a model or survey Reliability and its Item Analysis. Cronbach's Coefficient Alpha can be defined as:

$$
\alpha_{c}=\left(\frac{Q}{Q-1}\right) \frac{\sum_{i=j} \operatorname{COV}\left(x_{i,} x_{j}\right)}{\operatorname{Var}\left(x_{0}\right)}\left(\frac{Q}{Q-1}\right) 1-\left(\frac{\sum_{j} \operatorname{Var}\left(x_{j}\right)}{\operatorname{Var}\left(x_{0}\right)}\right) c=1, . ., M, i, j=1, . ., Q
$$

Where, $\mathrm{M}$ indicates the number of variables considered, $\mathrm{Q}$ the number of individual indicators available, and $x_{0=\sum_{q=1 x j}^{Q}}$ is the sum of all individual indicators. C-alpha measures the portion of the total variability of the sample of individual indicators due to the correlation between indicators. It increases to the number of individual indicators and with the covariance of each pair. If no correlation exists and individual indicators are independent, then $\mathrm{C}$-alpha is equal to zero, while if individual indicators are perfectly correlated, C-alpha is equal to one.

\section{Structural Equation Modeling}

Structural equation modeling (SEM) is a very general, mostly linear, predominantly cross-sectional statistical modeling. Factor analysis, path analysis, and regression all represent special cases of SEM. SEM is a largely confirmatory, rather than exploratory, technique, that is, a researcher is more likely to use SEM to determine whether a certain model is valid, rather than use SEM to find a goodness of fitting model. SEM is a quantitative research technique that can also incorporate qualitative methods. The model is used to show the causal relationships between variables. The relationships 
shown in SEM represent the hypotheses of the researchers. SEM produces data in a visual display, and this is part of its appeal. SEM is designed to look at the complex relationships between variables and to reduce the relationships to visual representations (Byrne, 2001; Khadka, 2016).

A generalized least squares estimation and maximum likelihood estimation was developed Kullback and Leibler (1951). Following estimation equation is 'scale-free' least squares estimation (SLs) used for data analysis:

$$
f_{S L S}\left(\Sigma^{(g)} ; S^{(g)}\right)=\frac{1}{2} \operatorname{tr}\left[D^{(g)-1}\left(S^{(g)}-\Sigma^{(g)}\right)\right]^{2}
$$

Where, $\mathrm{D}^{(\mathrm{g})}=\operatorname{diag}\left(\mathrm{S}^{(\mathrm{g})}\right)$

Maximum likelihood estimation is the additional estimation equation presented as:

$$
\begin{array}{r}
f\left(\Sigma^{(g)} ; S^{(g)}\right)=\frac{1}{2} \operatorname{tr}\left[K^{(g)-1}\left(S^{(g)}-\Sigma^{(g)}\right)\right]^{2} \\
\text { with }, K^{(g)}=\left(\hat{y}_{M L}\right)
\end{array}
$$

$\hat{\mathrm{Y}}_{\mathrm{ML}}$ is the maximum likelihood estimation of $\mathrm{Y}$.

Likewise, a distributional free method also used in this research. The expectations of using this method, are likely optimal results of the discrepancy function measure correctly without any assumption of the distribution of variables (Joreskog \& Sorbom, 1982). This is the ideal situation introduced into covariance structure analysis by the asymptotically distribution-free (ADF) method of Browne (1984) and the minimum distance method of Chamberlain (1982), which is identical:

$$
C(\alpha, a)=[N-r]\left[\frac{\sum_{g=1}^{G} N^{(g)} f\left(\mu^{(g)}, \Sigma^{(g)}, \bar{X}^{(g)}, S^{(g)}\right.}{N}\right][N-r] F(\alpha, a)
$$

Other statistics for data analysis are used, goodness-of-fit indices called GFI (Goodness of Fit) and AGFI (Adjusted GFI) introduced by Hooper, Coughlan and Mullen (2008). The GFI indicates goodness-of-fit, and the AGFI attempts to adjust the GFI for the complexity of the model. Two other well- known measures are the Tucker-Lewis Index (TLI) (Tucker \& Lewis, 1973), better known as the Non-Nonned Fit Index (NNFI), 
and the Normed Fit Index NFI (Bentler \& Bonett, 1980). Both the NNFI and the NFI adjust to the complexity of the model. Simulation research shows that all these indices still depend somewhat on sample size, while TLT and NNFI show the best overall performance. If the model fits perfectly, the fit indices should have the value 1. Usually, a value of at least 0.90 is required to accept a model, while a value of at least 0.95 is required to judge the model fit as 'good.' However, these are just rales of the thumb (Bollen \& Joreskog, 1985).

\section{RESULT AND DISCUSSION}

\section{Demographics}

One hundred twenty respondents associated with different departments of commercial banks of Kathmandu Valley participated on providing response on risk management, credit, accounts, treasury, trade to finance, internal audit and compliances, and the branch manager. The age of banking has been selected, less than ten years to above twenty years.

Among the total respondents, fifty-four percent were a manager and forty-six percent were bank officers. The level of experience of the respondents ranged from between one year to above ten years. About half of the respondents had more than five years of experience. According to the education classification, fifty-one percent staff were a master degree holder, seven percent were chartered accountant's degree holder and forty-two percent of the staff were bachelor degree holder. Thirty-seven percent of the staff received training as risk management, sixty-three percent has not received training. Among one hundred twenty respondents, fifty respondents regarded the credit risk as the most important risk being faced by the sample banks, followed by operational risk, interest rate risk of the frequencies of fifty-eight, thirty-five and fifteen respectively. Four important methods of risk identification being used by sample banks were an inspection by the bank risk manager, financial statement analysis, audits or physical inspection, and risk survey respectively.

\section{Statistics of Cronbach Coefficient Alpha}

The correlation is high, then there is evidence that the individual indicators measures the same underlying construct. Therefore, a high c-alpha, or equivalently a high reliability, indicates that individual indicators measures the latent innovation well. 
Cronbach's Alpha $(\alpha)$ used to measure the model exceeded 0.9, indicating the excellent level of internal consistency.

Table 1: Cronbach's Coefficient Alpha Risk Management Aspects and Components

\begin{tabular}{lll}
\hline Risk Management Aspect & Cronbach's alpha & $\begin{array}{l}\text { Number of } \\
\text { Questions }\end{array}$ \\
\hline Risk Management Practices & 0.967 & 7 \\
Understanding of Risk Management & 0.873 & 7 \\
Board Oversight & 0.950 & 7 \\
Credit Risk Analysis, & 0.934 & 7 \\
Averageof RMA & $\mathbf{0 . 9 8 0}$ & \\
Risk Management Component & & \\
Risk Identification & 0.982 & 7 \\
Risk Assessment and Measurement & 0.961 & 7 \\
Risk Monitoring & 0.962 & 7 \\
Risk Control & 0.948 & 7 \\
Average of RMC & $\mathbf{0 . 9 8 9}$ & \\
\hline
\end{tabular}

In Table 1,the value of Cronbach's Alpha based on standardized items is presented. The respective structures of this research model of all cases exceeded 0.90, thus the value indicating excellent internal consistency, which specifies the average Cronbach's Alpha based on standardized items is 0.980 for Risk Management Aspect and 0.989 for Risk Management Component. The statistical value indicates that the data are an excellent level of reliability and validity of internal consultancy, and about 2 percent and one percent data are an error in this case.

\section{Model Test}

The first data set, of resulting the model fits, which a chi-square of 462 and 28 degrees of freedom and a p-value of 0.000 .Assuming that the default model is correct, the probability of getting a discrepancy as large as 462 is 0.000 . For a good model fit, we want the Chi Square statistic to be not significant. In this case, the model was significant. PRATIO is 0.26 , PNFI is 0.23 and PCFI are 0.23. Likewise, RMSEA is 0.36 , PCLOSE is 0.000 , which indicating that the model is supported perfectly. The goodness of fit TLI is 0.58 and the NFI is 0.883 , both values are close to one, which indicate a very good fit of model. The value of RFI in both conditions close to one which is 0.87 and the value indicate a good 
fit of the model. Likewise, IFI value is 0.984 and IFI value close to one indicates a good fit. The value of TLI is 0.77 this indicates a good level of model fit. The value of CFI 0.90 or close to one indicates a very good fit, by convention, the CFI should be equal to or greater than one. RMR is 0.077 , GFI is 0.745 , AGFI is 0.90 and PGFI are 0.714 , these also show that the goodness of fit the model is very good.

Likewise, the second set of data and the resulting of model fits, which a chi-square of 41.755 and 7 degrees of freedom and a p-value of 0.000. Assuming that the Default model is correct, the probability of getting a discrepancy as large as 41.755 is 0.000 . For a good model fit, we want the Chi Square statistic to be not significant. In this case, the model was significant. PRATIO is 0.194, PNFI is 0.191 and PCFI is 0.191. Likewise, RMSEA is 0.204 , PCLOSE is 0.000 , which indicating that the model is supported perfectly. The goodness of fit TLI is 0.917 and the NFI are 0.981 , both the values are close to one, the value indicate a very good fit of NIF. The value of RFI in both conditions close to one which is 0.902 and the value indicate a good fit of the model. Likewise, IFI value is 0.984 and IFI value close to one, this value indicates a good fit of IFI. The value of TLI is 0.917 , this indicates that the very good level of TLI model fit. The value of CFI 0.984 or close to one, which indicates excellent fit, by convention, the CFI should be equal to or greater than one. RMR is 0.018 , GFI is 0.938 , AGFI is 0.803 and PGFI are 0.946 , these also show that the goodness of fit the model is excellent.

\section{Maximum Likelihood Estimates}

The Maximum Likelihood Estimates of Regression Weights is presented Table 2. The statistics show that the estimation of regression of all variables explains the positive relation between latent variables.

The probability of getting a critical ratio as larger than 10.652, the absolute value is less than 0.001 for all variables. The regression weight for F1 implies to RPM2, and F2_F8_2 to LOG_NPROFIT in the prediction is significantly different from zero at the 0.001 level. In all, a situation the maximum likelihood estimation is applied. Some selected variables and their results of Maximum Likelihood Estimates of Regression Weights are interpreted in individually as an example.

The Standardized Regression Weights Estimate also described. If the value of F1 goes up by one standard deviation, RPM_1 goes up by 0.919 standard deviations. If F2_F8 goes up by one standard deviation, URAIM goes up by 0.831 standard deviations. Likewise, when F2_F8 goes up by one standard deviation, LOGN_PROFIT goes up by 0.336 standard deviations. 
Table 2: Maximum Likelihood Estimates Regression Weights and Standardized Regression Weights Estimate

\begin{tabular}{|c|c|c|c|c|c|c|c|c|}
\hline & & & Estimate & S.E. & C.R. & $\mathbf{P}$ & Label & Estimate \\
\hline$\overline{R P M} 1$ & $<--$ & F1 & 1.000 & & & & & .919 \\
\hline RPM 2 & $<--$ & F1 & .745 & .070 & 10.652 & $* * *$ & par 1 & .757 \\
\hline RPM_3 & $<---$ & F1 & .891 & .058 & 15.262 & $* * *$ & par_2 & .888 \\
\hline RPM_4 & $<---$ & F1 & 1.056 & .051 & 20.731 & $* * *$ & par_3 & .967 \\
\hline RPM_5 & $<---$ & F1 & .976 & .054 & 18.054 & $* * *$ & par_4 & .933 \\
\hline RPM_6 & $<---$ & F1 & 1.003 & .070 & 14.382 & $* * *$ & par_5 & .864 \\
\hline RPM_7 & $<---$ & F1 & .961 & .064 & 15.080 & $* * *$ & par_6 & .874 \\
\hline URAIM & $<--$ & F2_F8 & 1.000 & & & & & .831 \\
\hline BASMO & $<--$ & F2_F8 & 1.238 & .085 & 14.530 & $* * *$ & par_7 & .960 \\
\hline CRA & $<--$ & F2_F8 & 1.038 & .073 & 14.219 & $* * *$ & par_8 & .944 \\
\hline RI & $<---$ & F2_F8 & 1.491 & .097 & 15.452 & $* * *$ & par_9 & .986 \\
\hline RAM & $<--$ & F2_F8 & 1.201 & .096 & 12.456 & $* * *$ & par_10 & .886 \\
\hline RM & $<--$ & F2_F8 & 1.229 & .082 & 15.043 & $* * *$ & par_11 & .975 \\
\hline $\mathrm{RC}$ & $<---$ & F2_F8 & 1.103 & .074 & 14.839 & $* * *$ & par_12 & .970 \\
\hline LOGN_PROFIT & $<---$ & F2_F8 & .190 & .054 & 3.553 & $* * *$ & par_62 & .336 \\
\hline
\end{tabular}

When F1 goes up by one, RPM_2 goes up by 0.745 .The regression weights to estimate, 0.745 has a standard error of about 0.070 . The regression weight estimate by the estimate of its standard error gives $\mathrm{z}=0.745 / 0.070=10.652$. In addition, the regression weight estimate is 10.652 standard errors above zero. The probability of getting a critical ratio as large as 10.652 in absolute value is less than 0.001. In other words, the regression weight for F1 in the prediction of RPM_2 is significantly different from zero at the 0.001 level. Likewise, if F1 drives up by 1, RPM_3 drives up by 0.891 . The regression weights to estimate, 0.891 , has a standard error of about 0.058 . The regression weight estimate by the estimate of its standard error gives $z=0.891 / 0.058=15.262$, and, regression weights to estimate is 15.262 standard errors above zero. The probability of getting a critical ratio as large as 15.262 in absolute value is less than 0.001 . This indicates the regression weight for F1 in the prediction of RPM_3 is significantly different from zero at the 0.001 level.

Moreover, When F1 changed by 1, RPM_4 change by 1.056 . The regression weights to estimate, 1.056, has a standard error of about 0.051 . The regression weight estimate by the estimate of its standard error gives $z=1.056 / 0.051=20.731$. Which indicates, the regression weight estimate is 20.731 standard errors above zero. The probability of getting a critical ratio as large as 20.731 in absolute value is less than 0.001 . Another latent variable F2_F8 changed by 1, BASMO changed by 1.238. The regression weights to estimate, 1.238 , has a standard error of about .085 . The regression weight estimate by 
the estimate of its standard error gives $z=1.238 / 0.085=14.530$. The regression weight estimate is 14.53 standard errors above zero. The probability of getting a critical ratio as large as 14.53 in absolute value is less than 0.001, the regression weight for F2_F8 in the prediction of BASMO is significantly different from zero at the 0.001 level.

The regression results from latent variable to numerical variable, as F2_F8 variation by one, LOGN_PROFIT variation by 0.19 . The statistics indicate that staff member sounds understanding of risk and its management practice in commercial banks, only this factor contribute about $19 \%$ profit. In other words, minimizing the risk of 1 scale and maximizing the profit about $19 \%$. The regression weights to estimate, 0.190 , has a standard error of about 0.054 . The regression weight estimate by the estimate of its standard error gives $z=0.190 / 0.054=3.553$. In addition, the regression weight estimate is 3.553 standard errors above zero. The probability of getting a critical ratio as large as 3.553 in absolute value is less than 0.001 . The regression weight for F2_F8 in the prediction of LOGN_PROFIT is significantly different from zero at the 0.001 level (two-tailed). The average mean value of seven statements of an understanding of risk and its management is 5.98 .

Likewise, the average mean value of senior management oversight, is 6.02. The average mean value of credit risk analysis is 6.39 and the average mean value of risk management practice, 5.93. Moreover, average mean values risk management component (risk identification) is 5.87. The average mean value risks assessment and measurement is 6.03 , and average mean value risk monitoring is 6.33 . The average mean value of risk control is 6.25 in seven bipolar scales. The average value of the mean of the mean are 6.10 , which indicates that about $87 \%$ respondents agree with all statements, only $13 \%$ data are an error. According to the statistics of the respondents, they understand they are practicing the risk management in their organization and successfully maximized their profit.

The output of statistics of regression weights and unstandardized and standardized regression weights, implied covariances, implied correlations and residual covariances, intercepts and their relationship are illustrated with Figure 1. 
Figure 1: Graphs of Structural Equation Modeling of the Relationship between Variables

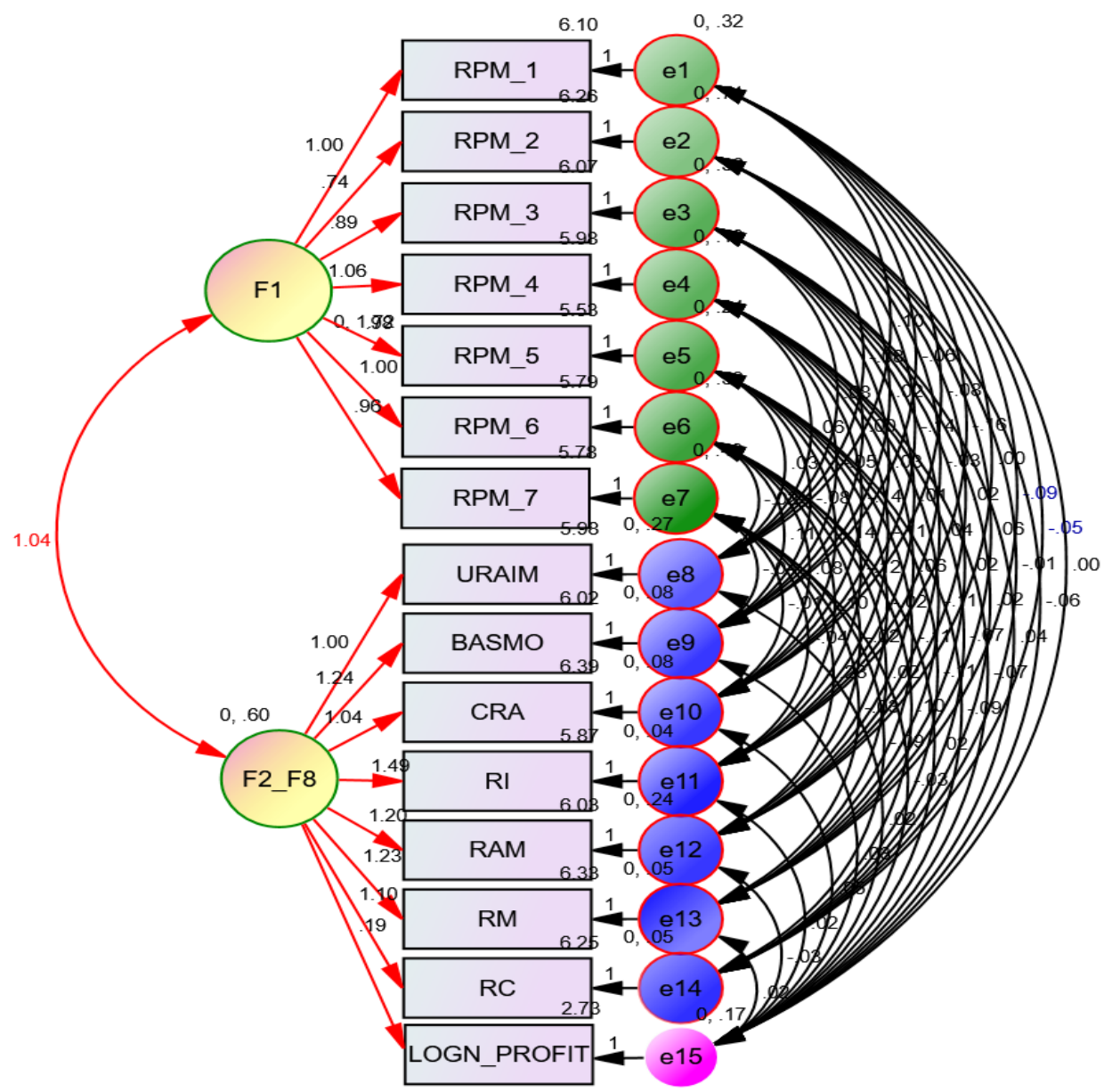

Another regression result from Maximum Likelihood Estimates and this result is based on quantitative data including net profits of the commercial banks in between 2010 to 2015. The results are presented in Table 3. 
Table 3: Maximum Likelihood Estimates Regression Weights and Standardized Regression Weights Estimate

\begin{tabular}{llllllll}
\hline & & Estimate & S.E. & C.R. & P & Label & Estimate \\
\hline RPM & $<---$ URAIM & .209 & .053 & 3.952 & $* * *$ & par_2 & .156 \\
RPM & $<--$ BASMO & .399 & .068 & 5.901 & $* * *$ & par_3 & .317 \\
RPM & $<---$ CRA & .304 & .094 & 3.242 & .001 & par_4 & -.202 \\
RPM & $<---$ RAM & .430 & .071 & 6.029 & $* * *$ & par_5 & .354 \\
RPM & $<---$ RM & .366 & .095 & 3.845 & $* * *$ & par_6 & .284 \\
RPM & $<---$ RC & .127 & .098 & 2.267 & .051 & par_7 & .088 \\
RPM & $<---$ RI & .053 & .096 & 2.549 & .052 & par_29 & .049 \\
LOGN_PROFIT & $<---$ RPM & .105 & .030 & 3.465 & $* * *$ & par_1 & .303 \\
\hline
\end{tabular}

If the variable URAIM change by 1, RPM change by 0.209 . The regression weights to estimate, 0.209 , has a standard error of about 0.053 . Dividing the regression weight estimate by the estimate of its standard error gives $z=0.209 / 0.053=3.952$. The probability of getting a critical ratio as large as 3.952 in absolute value is less than 0.001 . The regression weight for URAIM in the prediction of RPM is significantly different from zero at the 0.001 level. But CRA variable goes up by 1, RPM goes down by 0.304 . The regression weights to estimate, -0.304 , has a standard error of about 0.094 . The regression weight estimate by the estimate of its standard error gives $z=-0.304 / 0.094=-3.242$. In addition, the regression weight estimate is 3.242 standard errors below zero. The probability of getting a critical ratio as large as 3.242 in absolute value is 0.001 .

Likewise, all explanatory variables go up by one scale, RMP variable goes by about $27 \%$ point and again the variable RPM goes up by 1 scale point, LOGN_PROFIT goes up by 0.105 . The regression weights to estimate, 0.105 , has a standard error of about 0.030 . Dividing the regression weight estimate by the estimate of its standard error gives $\mathrm{z}=0.105 / 0.030=$ 3.465. The probability of getting a critical ratio as large as 3.465 in absolute value is less than 0.001. Including LOGN_PROFIT with RMP variable, all other variables is a positive relation and statistically significant at a $99 \%$ confidence level. The result shows, that the employee of Nepalese commercial banks, good knowledge about, risk management aspect including an understanding of risk and its management, board and senior management oversight, credit risk analysis, risk management practice. Likewise, knowledge about risk management component and its components risk identification, risk assessment, and measurement, risk monitoring, risk control. Thus, this indicates understanding the risk drives means minimizing the risk which leads to them high points the profit maximized by $10.5 \%$ respectively. Graph of maximum likelihood of the relationship between controlled variables, an explanatory variable and proxy and variables is presented in Figure 2. 
Figure 2: Graph of Maximum Likelihood of the Relationship Variables

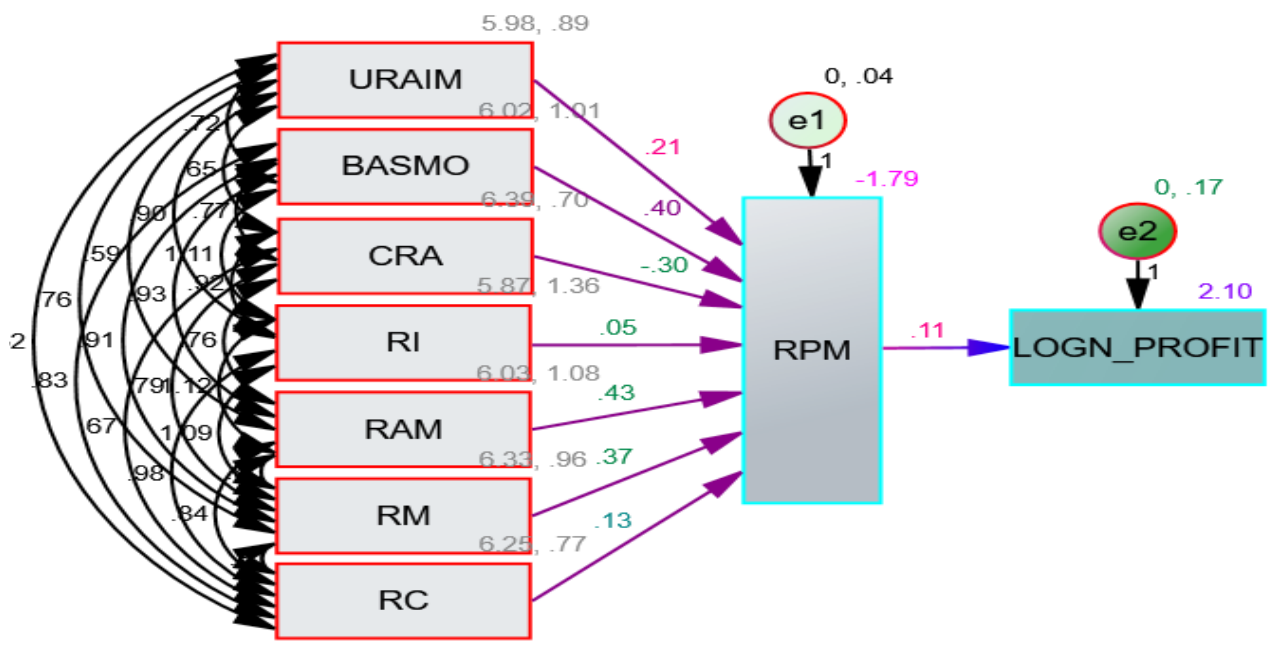

The implied covariance statistics given in Table 4, which indicates that all satisfied with RI, RC, RM, RAM, CRA, URAIM and RPM and LOGN_PROFIT cases and net profit move in the same direction. In Table 4 implied covariances for all variables is presented.

Table 4: Implied Covariances for All variables

\begin{tabular}{llllllllll}
\hline & RI & RC & RM & RAM & CRA & BASMO URAIM & RPM & $\begin{array}{c}\text { LOGN } \\
\text { PROFIT }\end{array}$ \\
\hline RI & 1.360 & & & & & & & & \\
RC & .977 & .767 & & & & & & & \\
RM & 1.089 & .813 & .956 & & & & & & \\
RAM & 1.116 & .845 & .896 & 1.082 & & & & & \\
CRA & .921 & .668 & .785 & .760 & .700 & & & & \\
BASMO & 1.111 & .828 & .911 & .927 & .774 & 1.008 & & & \\
URAIM & .903 & .616 & .756 & .592 & .646 & .721 & .888 & & \\
RPM & 1.427 & 1.066 & 1.179 & 1.222 & .978 & 1.213 & .934 & 1.593 & \\
LOGN_ & .150 & .112 & .124 & .128 & .103 & .128 & .098 & .167 & .192 \\
PROFIT & .158 & & & & & & & & \\
\hline
\end{tabular}

The correlation statistics of Table 5 reflects the positive relation between the extent of all explained variable and the proxy and explanatory variables as expected in commercial banks in Nepal. The correlation coefficient between RI, RC, RM, RAM, CRA, URAIM 
and RPM and LOGN_PROFIT, are of considerable degree, and the coefficient value is, 60 and greater for individual variables. The statistic indicates increase the level of understanding of risk management increasedto profit by theirorganization of a substantial degree.

Table 5: Implied Correlations for All variables

\begin{tabular}{lccccccccc}
\hline & RI & RC & RM & RAM & CRA & BASMO & URAIM & RPM & $\begin{array}{c}\text { LOGN_ } \\
\text { PROFIT }\end{array}$ \\
\hline RI & 1.000 & & & & & & & & \\
RC & .956 & 1.000 & & & & & & & \\
RM & .955 & .949 & 1.000 & & & & & & \\
RAM & .920 & .927 & .881 & 1.000 & & & & & \\
CRA & .944 & .911 & .960 & .873 & 1.000 & & & \\
BASMO & .949 & .942 & .928 & .888 & .921 & 1.000 & & & \\
URAIM & .822 & .746 & .820 & .604 & .819 & .762 & 1.000 & & \\
RPM & .969 & .964 & .955 & .931 & .927 & .958 & .786 & 1.000 & \\
LOGN_ & .293 & .292 & .289 & .282 & .281 & .290 & .238 & .303 & 1.000 \\
PROFIT & & & & & & & & & \\
\hline
\end{tabular}

Likewise, all covariance between the variable positive and probability value less than 0.001 . The estimated correlation between BASMO and RI is 0.949. The maximum value of correlation is 0.960 estimated correlation between the CRA and RM and a minimum value of correlation is 0.604 estimated. The result shows that correlation between all variables is positively and exceedingly correlated.

In Table 6covariances and correlations group, number one is presented. The covariance between BASMO and RI is estimated to be 1.111. The covariance estimate, 1.111, has a standard error of about.148. The covariance estimate by the estimate of its standard error gives $\mathrm{z}$ is 7.509. In other words, the covariance estimate is 7.509 standard errors above zero. The probability of getting a critical ratio as large as 7.509 in absolute value is less than 0.001 . The covariance between BASMO and RI is significantly different from zero at the 0.001 . 
Table 6: Covariances and Correlations

\begin{tabular}{lllllllll}
\hline & & & Estimate & S.E. & C.R. & P & Label & Estimate \\
\hline BASMO & $<-->$ & RI & 1.111 & .148 & 7.509 & $* * *$ & par_8 & .949 \\
BASMO & $<-->$ & RAM & .927 & .128 & 7.242 & $* * *$ & par_9 & .888 \\
BASMO & $<-->$ & RM & .911 & .123 & 7.419 & $* * *$ & par_10 & .928 \\
BASMO & $<-->$ & RC & .828 & .111 & 7.478 & $* * *$ & par_11 & .942 \\
URAIM & $<-->$ & CRA & .646 & .093 & 6.913 & $* * *$ & par_12 & .819 \\
CRA & $<-->$ & RAM & .760 & .106 & 7.175 & $* * *$ & par_13 & .873 \\
CRA & $<-->$ & RM & .785 & .104 & 7.553 & $* * *$ & par_14 & .960 \\
CRA & $<-->$ & RC & .668 & .091 & 7.347 & $* * *$ & par_15 & .911 \\
URAIM & $<-->$ & RI & .903 & .130 & 6.927 & $* * *$ & par_16 & .822 \\
URAIM & $<-->$ & RAM & .592 & .105 & 5.643 & $* * *$ & par_17 & .604 \\
URAIM & $<-->$ & RM & .756 & .109 & 6.919 & $* * *$ & par_18 & .820 \\
URAIM & $<-->$ & RC & .616 & .094 & 6.525 & $* * *$ & par_19 & .746 \\
RM & $<-->$ & RI & 1.089 & .145 & 7.535 & $* * *$ & par_20 & .955 \\
RC & $<->$ & RI & .977 & .130 & 7.540 & $* * *$ & par_21 & .956 \\
RAM & $<-->$ & RM & .896 & .124 & 7.211 & $* * *$ & par_22 & .881 \\
RAM & $<-->$ & RC & .845 & .114 & 7.416 & $* * *$ & par_23 & .927 \\
RM & $<-->$ & RC & .813 & .108 & 7.510 & $* * *$ & par_24 & .949 \\
URAIM & $<-->$ & BASMO & .721 & .109 & 6.614 & $* * *$ & par_25 & .762 \\
BASMO & $<-->$ & CRA & .774 & .105 & 7.392 & $* * *$ & par_26 & .921 \\
CRA & $<->$ & RI & .921 & .123 & 7.487 & $* * *$ & par_27 & .944 \\
RAM & $<-->$ & RI & 1.116 & .151 & 7.387 & $* * *$ & par_28 & .920 \\
\hline
\end{tabular}

The maximum value of correlation is 0.960 estimated correlation between the CRA and RM and a minimum value of correlation is 0.604 estimated. The result shows that correlation between all variables is positively and exceedingly correlated.

\section{CONCLUSION}

The three important types of risk of commercial banks of Nepal are a credit risk, operational risk, and interest rate risk. Commercial banks of Nepal mainly use risk identification methods like inspection by the bank risk manager, financial statement analysis, audits or physical inspection, and risk survey. Staff members of commercial banks of Nepal have a good understanding of the risks and its management. They have clearly understood the various types of risk of their banks are currently exposed to inherent in the banking operations. Further, they understand that managing risk is crucial to the success of banks. This might give an indication of the ability of these 
banks to manage risks efficiently in the future. The commercial banks of Nepal have shown to increase efficiency in managing credit risk. Though the level of NPL of some of the banks is high. Overall risk management practice is also satisfactory. The most of the banks has taken risk management as one of the major objectives. This signifies that they have viewed risk management practices as acore part of the management of the bank. In the context of Nepalese commercial banks, most of the components of risk management are very sound.

Thereisasignificantrelationshipbetween risk management practices and understanding of risk and its management, board and senior management oversight, credit risk analysis, risk identification, risk assessment and measurement, risk monitoring, and risk control. Board and senior management oversight (BASMO), risk assessment and measurement (RAM), ownership structure (OS) and presence of separate risk manager (PSRM) are the most influencing variables in risk management practices. The nature of ownership structure of commercial banks of Nepal significantly affects the risk management practices, these practices lead to their profit maximization.

As a final point, the risk management has become a vital function that requires specialized knowledge, skills, and expertise; Nepalese BFIs need to give proper effort in the area of risk management practices (RMPs) and build sound expertise along with updated methods to manage risk. In order to make the risk management effective against the commercial banks of Nepal, the major types of risks being faced by commercial banks of Nepal, that is, credit risk is the first, second is operational risk, and last is interest rate risk. This should need to be emphasized by the concerned banks. Moreover, the banks should give the special focused to follow the Basel principles of management of different risks in addition to the NRB's risk management guideline. The risk identification, the most important predictor of risk management, should be strengthened by commercial banks to identify the risks and take remedial measures earlier.

\section{References}

Adhikari, P. (2014). Corporate governance practices in commercial banks in Nepal. Abhinav International Monthly Refereed Journal of Research in Management $\mathcal{E}$ Technology, 3(9), 55-64. Retrieved from https://abhinavjournal.com/journal/ index.php/ISSN-2320-0073/article/viewFile/416/pdf.

Adu, L. A.,\& Adjare, D. T. (2015). Determinants of credit risk of commercial banks in Ghana. SSRN Electronic Journal, 1-7. DOI: 10.2139/ssrn.2679100. 
Afande, F. O. (2014). Credit risk management practices of commercial banks in Kenya. European Journal of Business and Management, 6(34), 21-61. http://www.iiste.org/ journals.

Al-Tamimi, H. A. H.,\& Al-Mazrooei, F. M. (2007). Banks' risk management: A comparison study of UAE national and foreign banks. The Journal of Risk Finance, 8(4), 394-409.

Arrawatia, R., Misra, A., Dawar, V., \& Maitra, D. (2018). Bank competition in India: Some new evidence using risk-adjusted Lerner index approach. Journal for Research and Studies on Insurance and Financial Risk Management, (7), 44), 2-12. doi: 10.3390/risks7020044 www.mdpi.com/journal/risks.

Awdeh, A., EL-Moussawi, C. \& Machrouh, F. (2011). The effect of capital requirements on banking risk. International Research Journal of Finance and Economics,66, 134146. Retrieved from http://www.eurojournals.com/finance.htm.

Bentler, P. M.,\& Bonett, D. G. (1980). Significance tests and goodness of fit in the analysis of covariance structures. Psychological Bulletin, 88, 588-606.

Bollen, K. A. \& Joreskog, K. G. (1985). Uniqueness does not imply identification: A note on confirmatory factor analysis. Sociological Methods and Research, 14, 155-163.

Browne, M. W. (1984). Asymptotically distribution-free methods for the analysis of covariance structures. British Journal of Mathematical and Statistical Psychology, 37, 1-21. http://www2.gsu.edu/ mkteer/discrep.html\#refs.

Byrne, B. M. (2001). Structural equation modeling with AMOS: Basic concepts, applications, and programming. Mahwah, NJ: Erlbaum.

Chamberlain, G. (1982). Multivariate regression models for panel data. Journal of Econometrics, 18(1), 5-46. Retrieved from http://www.sciencedirect.com/ science/article/pii/0304-4076(82)90094-X.

Coase, R. H. (1937). The nature of the firm. Economica, New Series, (4),16. Retrievedfromhttp://www.jstor.org/about/terms.html.

Cronbach L. J. (1951). Coefficient alpha and the internal structure of tests. Psychometrika, 16, 297-334. Retrieved fromhttp://kttm.hoasen.edu.vn/sites/default/ files/2011/12/22/cronbach_1951_coefficient_alpha.pdf.

Guill, G.D. (2009). Bankers trust and the birth of modern risk management. Financial Institutions Center, The Wharton School, University of Pennsylvanian, USA. 
Heffernan, S. (2005). Modern banking. John Wiley \& Sons Ltd, The Atrium, Southern Gate, Chichester, West Sussex PO19 8SQ, England. Retrieved from www. wileyeurope.com or www.wiley.com.

Hooper, D., Coughlan, J., \& Mullen, M. (2008). Structural equation modeling: Guidelines for determining model fit. Electronic Journal of Business Research Methods, 6(1), 53-60. Retrieved from http://arrow.dit.ie/buschmanart.

Joreskog, K. G., \& Sorbom, D. (1982). Recent developments in structural equation modeling. Journal of Marketing Research,19, 404-416. Retrieved from http:// personal.psc.isr.umich.edu/yuxie-web/files/pubs/Articles/Joreskog Sorbom1982.pdf.

Khadka, C.B. (2016). Effectiveness of teaching economics in higher secondary school level. Economic Journal of development Issues, 21\& 22(1-2), 99-126.

Kullback, S. \& Leibler, R. A. (1951). On information and sufficiency. Annals of Mathematical Statistics, 22, 79-86.

Kumah, S. P. \&Sare, Y. A. (2013). Risk management practices among commercial banks in Ghana. European Journal of Business and Management, 5(20), 185-191. Retrievedfrom http://www.iiste.org.

Mehar, Y. S. (2012). Operational risk management in Indian banks: Issues and challenges. Indian Journal of Economics \& Business, 11(1), 25-40.

Mehta, A. \& Bhavani, G. (2017). What determines banks' profitability? Evidence from emerging markets the case of the UAE banking sector. Accounting and Finance Research, 6(1), 77-88. http://dx.doi.org/10.5430/afr.v6n1p77.

Mutava, , P. M. \& Ali, A. I. (2016). Effects of credit risk management on financial performance of commercial banks in Mombasa County. Research Journal of Finance and Accounting, 7(17), 15-22. http://www.iiste.org.

Nepal Rastra Bank. (2010-2015). Banking and financial statistics-2010-2015. Baluwatar, Kathmandu: Author . (2018). Risk Management Guidelines for Banks and Financial Institutions. Nepal Rastra Bank Bank Supervision Department, Kathmandu: Author. Retrieved from https://www.nrb.org.np/bfr/directives/Guidelines-2018-new.pdf.

Nguyen, T. T. Q.,\& Christopher, G. (2019). Bank risk management: A regulatory perspective. Perspectives on Risk, Assessment and Management Paradigms, Ali G. Hessami, Intech Open. DOI: 10.5772/intechopen.79822. Available from: https://www. intechopen.com/books/perspectives-on-risk-assessment-and-managementparadigms/bank-risk-management-a-regulatory-perspective. 
Odit, M. P., Dookhan, K., \& Marylin, J. C. (2011). The impact of risk management and portfolio diversification on the Mauritian banking sector. International Journal of Management $\mathcal{E}$ Information Systems, 15(2),117-128.DOI: 10.19030/ijmis. v15i2.4161.

Shanmugam, B., \& Bourke, P. (1990). The management of financial institutions(1990 e.d.). Addison-Wesley.

Tucker, L. R. \& Lewis, C. (1973). A reliability coefficient for maximum likelihood factor analysis. Psychometrika, 38, 1-10.

\section{ACKNOWLEDGEMENT}

I am very thankful to Mr. Deepesh Banepali, Assistant Director, Nepal Rastra Bank, for his valuable contribution for this research work. His help absolutely in questionnaire design, data collection and organization as well as reliability test are highly acknowledged. 